УДК 004.93'12

Kroshenko D., Molchan O.

\title{
Facial Recognition Technology
}

Belarusian National Technical University

Minsk, Belarus

Ever since the birth of first mankind, human beings have continually been seeking for personal possessions. From the very basics of food and clothes, to cars, houses, and the more recent substantial property of data and information, it is becoming increasingly important that such valuable assets be sheltered by means of security control.

Throughout history, the types of technologies used on the access control systems are countless. From the traditional systems such as security guards checking personal ID's to the very fundamentals of keypads and locks and password or entry code, the focus now has moved to the more advance technologies, particularly in today's multifaceted society. Organisations are continuously seeking for a more secure, suitable and economical way of property protection.

The problem associated with traditional mechanisms is that the possessions could be lost, stolen, forgotten, or misplaced. Furthermore, once in control of the identifying possession, any other unauthorised person could abuse the privileges of the authorised user. Therefore, there is a need of another approach to properly differentiate the correct (right) person from an impostor by positive identification of the person seeking access. Biometrics is one rising development in the field of access control system that provides true identification. Although the word "biometrics" sound very new and high tech, it is in fact the oldest form of identification known to man. Since the dawn of man, a person's face and 
voice was used to identify him/her [2]. The face is an important part of who you are and how people identify human. Except in the case of identical twins. The human face is arguably a person's most unique physical characteristics, while humans being have the innate ability to recognize and distinguish different faces for millions of years, computers are just now catching up [3]. Before the digital age, a hand written signature was the only method used by a person to assert a unique form of identification that was difficult to copy. Popular biometric systems in use today include fingerprint recognition, iris recognition, voice recognition, and facial recognition systems [2]. Border controls, airlines, airports, transport hubs, stadiums, mega events, concerts, conferences. Biometrics are playing a growing role not only in the real-time policing and securing of increasingly crowded and varied venues worldwide, but also in ensuring a smooth, enjoyable experience for the citizens who visit them. Biometric system offers the most accurate authentication solution and convenience. Biometrics systems can be integrated into any application that requires security, access control, and identification or verification of people. With biometric security, we can dispense with the key, the password, the PIN code; the access-enabler is human beings not something he know, or something in his possession [2].

Face recognition can often prove one of the best biometrics because images can be taken without touching or interacting with the individual being identified, and those images recorded and instantly checked against existing databases. Face recognition has come to be an active research area with numerous applications in recent years. Facial recognition is a crucial factor of everyday identification processes: human beings recognize and evaluate each other by means of the face. Whenever driving licences, identity and membership cards are checked or wherever access is controlled by security staff, the identity is verified by looking into 
somebody's face. Thus, unlike other biometric features, e.g. the fingerprint or iris recognition, facial recognition is a transparent procedure well-known to human beings. However, it has become obvious that the traditional way of identifying individuals is insufficient. There are certain limits to the natural recognition process carried out by human beings: The recognition performance is not only impaired by difficulties with the recognition of people from other ethnic origin or deceptions due to a different hairstyles or beards, but also by subjective impression based on a person's outward.

The requirement of successful personal identification in access control and in other cases leads to using the results of biometrics. Biometrics Face recognition is a passive, noninvasive method for verifying the identity of a person which offers the benefits of its unique facial technology in the form of customized overall solutions for the areas of access control, border control, ID-Management, search for criminals and video surveillance [2].

References:

1. The Threats and Benefits of Facial Recognition [Electronic resource]. - Mode of access: https://becominghuman.ai/thethreats-and-benefits-of-facial-recognition-what-should-weknow-17008f69ae74. - Date of access: 20.04.2020.

2. Facial Recognition Technology for Identification [Electronic resource]. $\quad-\quad$ Mode of access: https://ukdiss.com/examples/identification-process-of-human. - Date of access: 19.04.2020.

3. Essay: Facial recognition [Electronic resource]. - Mode of access: https://www.essaysauce.com/information-technologyessays/facial-recognition/. - Date of access: 20.04.2020. 